\title{
Depression and Stroke: Cause or Consequence?
}

\author{
Linda S. Williams, M.D. ${ }^{1}$
}

Depression after stroke is common. Although different opinions exist about the definition, diagnosis, and measurement of outcomes related to depression after stroke, there is little debate about the prevalence of depression symptoms and their impact on stroke survivors and their families. Depression after stroke has long been recognized as a common condition with many negative effects in the poststroke period, but more recently depression has also been identified as an independent stroke risk factor. Given that there are at least 500,000 new ischemic strokes yearly in the United States, a conservative estimate is that 150,000 U.S. stroke survivors develop poststroke depression each year. Because effective treatments exist but are likely underutilized for depression, this is an important example of an evidence-practice gap to which increased efforts to improve care should be made. Such efforts would likely improve not only patient symptoms but may also decrease stroke risk, influence stroke functional recovery, decrease mortality, and reduce poststroke health care utilization. This article provides an overview of depression diagnosis in stroke, reviews the epidemiology of poststroke depression and its associated morbidity and mortality, and reviews existing evidence on the treatment and prevention of poststroke depression.

KEYWORDS: Stroke, depression, recovery, risk factors

Objectives: On completion of this article, the reader will have an increased awareness of poststroke depression and the risk factors for developing post stroke depression.

Accreditation: The Indiana University School of Medicine is accredited by the Accreditation Council for Continuing Medical Education to provide continuing medical education for physicians.

Credit: The Indiana University School of Medicine designates this educational activity for a maximum of 1 Category 1 credit toward the AMA Physicians Recognition Award. Each physician should claim only those credits that he/she actually spent in the educational activity. Disclosure: Statement of disclosure has been obtained regarding the author's relevant financial relationships. The author has nothing to disclose.

Depression after stroke is common. The vast majority of the literature has studied depression after ischemic stroke only, not hemorrhagic stroke; therefore, the term "poststroke depression" (PSD) will be used here to indicate depression related to ischemic stroke unless otherwise specified. Although different opinions exist about the definition, diagnosis, and measurement of outcomes related to depression after stroke, there is little debate about the prevalence of depression symptoms and their impact on stroke survivors and their families. Given

Stroke Acute Management and Recovery; Editor in Chief, Karen L. Roos, M.D.; Guest Editor, Bradford B. Worrall, M.D., M.Sc. Seminars in Neurology, Volume 25, Number 4, 2005. Address for correspondence and reprint requests: Linda S. Williams, M.D., Health Services Research Center $(11 \mathrm{H})$ Neurology, Roudebush VA Medical Center, 1481 West 10th Street, Indianapolis, IN 46202. ${ }^{1}$ Center for Implementing EvidenceBased Practice, Roudebush VAMC; Associate Professor, Neurology, Indiana University School of Medicine; Research Scientist, Regenstrief Institute, Inc., Indianapolis, Indiana. Published 2005 by Thieme Medical Publishers, Inc., 333 Seventh Avenue, New York, NY 10001, USA. Tel: +1(212) 584-4662. 0271-8235,p;2005,25,04,396,409,ftx,en;sin00390x. 
that there are at least 625,000 new ischemic strokes yearly in the United States, a conservative estimate is that at least 185,000 U.S. stroke survivors develop PSD each year. Because effective treatments exist but are likely underutilized for depression, this is an important example of an evidence-practice gap to which increased efforts to improve care should be made. Such efforts not only would likely improve patient symptoms but may also influence stroke functional recovery, decrease mortality, and reduce poststroke health care utilization. This article provides an overview of depression diagnosis in stroke, reviews the epidemiology of PSD and its associated morbidity and mortality, and reviews existing evidence on the treatment and prevention of PSD.

\section{DEFINING DEPRESSION}

Depression is a syndromic condition that, like many disorders, is diagnosed and monitored by assessing symptoms. The most commonly used diagnostic algorithm is based on the Diagnostic and Statistical Manual, Fourth Version (DSM-IV) and includes criteria for major depression and minor depression as well as criteria for other categories of depressive disorders (Table 1). Diagnosis of major depression requires persistent low mood or loss of interest in most activities for at least 2 weeks, including some of the following symptoms to total at least five symptoms: weight change (increase or decrease), altered sleep pattern (too little or too much), lack of energy, poor concentration, agitation, reduced self-esteem, suicidal ideas or plans. Minor depression requires three or four of these symptoms, with at least one symptom being depressed mood or loss of interest, for at least 2 weeks.

PSD is typically defined simply as depression that develops after ischemic stroke. Most studies of PSD do not distinguish between major and minor depression diagnoses. Studies of PSD are also complicated by the varied time frames used in this definition, the methods of diagnosing depression, and the different population of stroke patients studied. ${ }^{1-4}$ Permeating these meth-

\section{Table 1 DSM-IV Symptoms of Major Depression}

At least one of these:

Depressed mood

Anhedonia

And some of these to total five symptoms present for at least 2 weeks:

Change in appetite/weight (increase or decrease)

Altered sleep pattern (increase or decrease)

Lack of energy

Difficulty concentrating

Agitation

Reduced self-esteem

Suicidal thoughts or plans odological difficulties is the theoretical problem of evaluating mental functioning in brain-injured patients. Potential difficulties include evaluating mood in patients with language, cognitive, and attentional disturbances and attributing somatic symptoms to mood disorders when the symptoms may be more strongly related to the neurological condition. ${ }^{3}$

Because physical symptoms are a common feature of the poststroke period and because physical symptoms like poor sleep and fatigue are part of the diagnostic assessment of depression yet are also common in nondepressed patients, some authors have questioned whether PSD is overdiagnosed in the poststroke period due to non-depression-related physical complaints. Although this hypothesis seems reasonable, it has not been convincingly demonstrated in a stroke cohort. Robinson and colleagues did not find "overdiagnosis" of PSD with only 2 to $3 \%$ of patients having solely somatic symptoms of depression, ${ }^{5}$ and we likewise found that although PSD patients had more severe physical depression symptoms after stroke, they did not have a greater number of physical depression symptoms compared with depressed older adults without stroke (Fig. 1). ${ }^{6}$ We also compared symptom endorsement on the Patient Health Questionnaire (PHQ)-9 items between depressed and nondepressed patients and found that all symptoms, including sleep, fatigue, appetite, and feeling slowed down or agitated, were at least five times more likely to be endorsed by depressed patients than nondepressed patients. ${ }^{7}$

Another key question for PSD diagnosis is how soon after stroke PSD can be reliably diagnosed. Because depression symptoms, and symptoms in general, are heightened at times of illness and elevated situational stressors, persons hospitalized for any condition report more depressive symptoms than those not hospitalized. This makes diagnosis of PSD difficult in the immediate poststroke period. DSM-IV diagnosis requires symptoms to be present for at least 2 weeks, so adherence to a diagnostic rather than a screening algorithm can be helpful in clarifying this issue. Stroke patients may also have symptoms like emotional lability or apathy as a manifestation of frontal stroke and not depression. ${ }^{8}$ The relationship between early emotionality and subsequent depression diagnosis in stroke patients has been studied, ${ }^{9,10}$ with most authors reporting some association between early emotionality and later depression. Although not all patients with emotionality meet criteria for PSD, these symptoms should prompt follow-up screening after 2 weeks as patients with early emotionality are probably at increased risk for developing PSD.

\section{SCREENING FOR DEPRESSION AFTER STROKE}

Several established depression screening tools have been validated in stroke cohorts, and at least one tool has been 


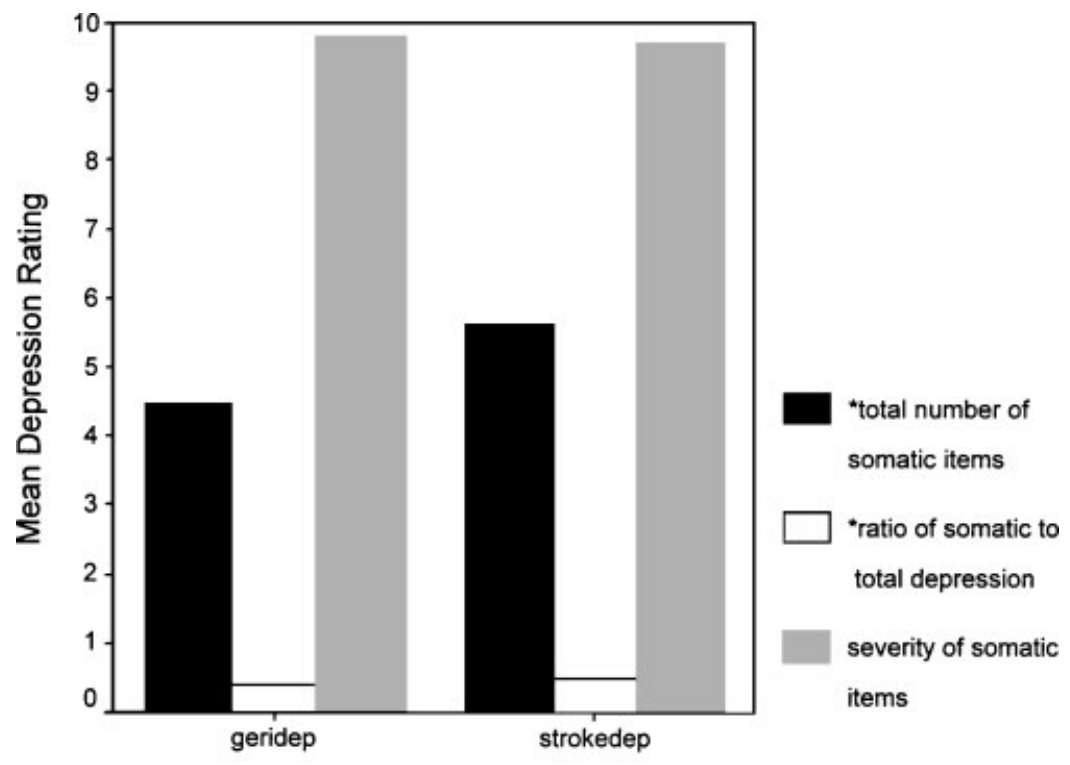

Geriatric depression vs. Post-stroke depression

Figure 1 Comparison of somatic symptom clusters in PSD versus geriatric depression patients. (PHQ-9 Copyright (C) 1999 Pfizer, Inc. All rights reserved. Reproduced with permission. PRIME MD TODAY is a trademark of Pfizer, Inc.)

developed specifically for depression screening in stroke survivors. ${ }^{7,11-15}$ Before evaluating or choosing a particular tool for use in a stroke population, it is important to understand some critical differences in screening tools. Some tools, like the Center for Epidemiology StudiesDepression (CES-D) and the Beck Depression Inventory, are designed to screen for depression but not to make a particular diagnosis (e.g., differentiate major depression from minor or other depression). Other tools, for example the Zung and the PHQ-9, are designed to be both a screening tool, with an established cut point to indicate patients with a high probability of depression diagnosis, and a diagnostic tool, where not just the overall score but the specific combination of symptoms are taken into consideration and validated against a psychiatric interview to establish diagnostic algorithms for the scales.

This important principle can be illustrated with the PHQ-9, a nine-item scale designed for use in outpatient primary care clinics, which assesses the nine DSM-IV depression symptom criteria for frequency of occurrence during the previous 2 weeks. As a screening tool, the nine items are summed, resulting in a score ranging from 0 (no depressive symptoms) to 27 (all nine symptoms occurring daily). ${ }^{16,17}$ In this use, a PHQ-9 score $\geq 10$ has been found to have $88 \%$ sensitivity and $88 \%$ specificity for a diagnosis of major depression. The first two items of the PHQ-9 assess depressed mood and anhedonia, and these two items (the PHQ-2) have also been tested as a depression screening tool in primary care clinics, with score $\geq 3$ identified as having $83 \%$ sensitivity and $92 \%$ specificity for identifying patients with major depression. As a diagnostic instrument, the PHQ-
9 can be used to identify patients with major depression if five or more of the nine symptoms have been present at least more than half the days of the past 2 weeks and if at least one of these five symptoms endorsed is either depressed mood or anhedonia. We have recently shown that the PHQ-9 performs well as a depression screening tool in stroke patients, with $91 \%$ sensitivity and $83 \%$ specificity for major depression and $78 \%$ sensitivity and $96 \%$ specificity for any depression diagnosis. ${ }^{7}$ Likewise, the PHQ-2 performed nearly as well with sensitivity of $83 \%$ and specificity of $84 \%$ for major depression and sensitivity $78 \%$ and specificity $95 \%$ for any depression diagnosis. The PHQ-2, however, can only be used as a screening tool, so patients with a score $\geq 3$ on this scale should be administered the remaining seven items for more complete assessment of depression symptoms (including suicidality) and to enable a precise diagnosis of depression.

\section{“POSTSTROKE" DEPRESSION: A MISNOMER?}

Another critical issue that has not been well studied is the timing of depression in relation to the stroke. Most commonly, any depression recognized after a stroke has occurred is termed PSD, and whether the depressive symptoms predated the stroke is not ascertained. In our ongoing trial of depression case management versus usual care in stroke survivors, preliminary data in 180 depressed subjects showed that $30 \%$ report being on an antidepressant at the time their stroke occurred. This is of interest not only because prior depression has been identified as a risk factor for the development of PSD but 
also because depression itself is increasingly recognized as a risk factor for stroke. Despite this conceptual complexity, for ease of use and convention, most authors and researchers continue to use the term "poststroke depression" to refer to any depression present after stroke, regardless of the timing of symptom onset. Further research is needed in this area to better understand depressive symptoms as a risk for stroke, and potential treatment and recovery implications for stroke survivors with longstanding versus more recent depressive symptoms.

\section{DEPRESSION AS A STROKE RISK FACTOR}

Depression and depressive symptoms have been recognized as a risk factor for cardiovascular disease and, more recently, as a risk factor for stroke. Although a review of the epidemiology of depression and other psychiatric disorders after myocardial infarction (MI) is beyond the scope of this review, Davies et al have provided a thorough review of the epidemiology and treatment of anxiety and depressive disorders in patients with cardiovascular disease. ${ }^{18}$ Several studies have found a link specifically between depressive symptoms and increased risk of stroke (Table 2). In a random sample of 1134 subjects aged 65 and older, prior stroke was associated with a sixfold increase in 2-year risk of depression, even when controlling for functional status, stroke risk factors, and prior depression symptoms. ${ }^{19}$ Similarly, in a 6-year prospective cohort study of nearly 2500 older adults, Ostir and colleagues found that stroke risk increased as scores on the CES-D increased (relative risk [RR] of stroke 1.04 for each 1-point CES-D increase) and, conversely, that positive affect scores had a strong inverse relationship with stroke (RR 0.74). ${ }^{20} \mathrm{In}$ this sample, the authors also demonstrated that baseline depressive symptoms were associated with less recovery in activities of daily living after stroke, MI, or hip fracture, suggesting that the negative impact of depression on recovery after an acute event is likely mediated via multiple physiologic, behavioral, and social mechanisms rather than by an effect on neural plasticity alone. ${ }^{21}$ Data from the NHANES study likewise showed that depression symptoms at baseline were associated with increased stroke risk during an average of 16 years of follow-up even after adjusting for demographic and other vascular risk factors (overall RR of stroke $1.73,95 \%$ confidence interval $[\mathrm{CI}]=1.30$ to 2.31). ${ }^{22}$ The relationship was strongest in blacks (RR of stroke 2.6) and only of borderline significance in white women $(\mathrm{RR}=1.52,95 \% \mathrm{CI}=0.97$ to 2.38$)$. This relationship has also been demonstrated in prospective cohorts from other countries, including the finding in a cohort of 901 Japanese adults aged 40 to 78 years that depressive symptoms increased the 10-year adjusted risk of subsequent ischemic stroke at least twofold. ${ }^{23}$ Whether this observed increase in stroke risk is specifically related to depression or is seen with other mental health disorders is not clear, but one Danish populationbased study demonstrated that stroke risk was increased $22 \%$ in older patients previously hospitalized for depressive disorder but not in those hospitalized for mania/ bipolar disorder. ${ }^{24}$ This relationship between depression symptoms and stroke does appear to be at least somewhat bidirectional, another factor that complicates its study. Known as the "vascular theory of late life depression," some studies find that the risk of depression in older adults without stroke increases as the number of cerebrovascular risk factors increases, presumably suggesting that depression is related to clinically silent, small-vessel cerebrovascular disease. ${ }^{25}$ However, in at least one study the relationship between vascular risk factors and depression was not seen in older adults who had a history of stroke. ${ }^{26}$ Further dissecting this complex issue will require longitudinal cohorts in which depression symptoms, vascular risk factors, and vascular outcomes are all well described. ${ }^{27}$

Depression symptoms have been linked not to just increased stroke risk but also increased stroke mortality. Analysis of more than 11,000 subjects in the Multiple Risk Factor Interventions Trial (MRFIT) cohort showed that depression symptoms were independently associated with all-cause mortality and cardiovascular disease mortality during 18 years of followup. ${ }^{28}$ Importantly, the increased cardiovascular mortality was due to increased stroke mortality (hazard ratio 2.0) but not to increased coronary heart disease mortality. Further support of this relationship was the observation of a linear trend between depression symptoms and

Table 2 Depression as a Stroke Risk Factor

\begin{tabular}{|c|c|c|c|}
\hline Study & $n$ & Depression Assessment & RR of Stroke (95\% Cl) \\
\hline Ostir et $\mathrm{al}^{20}$ & 2478 & CES-D & $1.04(1.01-1.09)$ for each 1-point increase on the CES-D \\
\hline Jonas et $\mathrm{al}^{22}$ & 6095 & Self-report (NHANES interview) & $1.73(1.30-2.31)$ \\
\hline Ohira et $\mathrm{al}^{23}$ & 901 & Zung SDS & $\begin{array}{l}1.9(1.1-3.5) \text { for total stroke, } 2.7(1.2-6.0) \text { for ischemic } \\
\text { stroke }\end{array}$ \\
\hline Nilsson et $\mathrm{al}^{24}$ & & Hospitalization for depression & $1.22(1.06-1.41)$ \\
\hline Everson et $\mathrm{al}^{29}$ & 6676 & Human Population Laboratory Depression scale & $1.54(1.06-2.22)$ for stroke mortality \\
\hline
\end{tabular}

CES-D, Centers for Epidemiologic Study-Depression scale; Zung SDS, Zung Self-rating Depression Scale. 
mortality, where mortality risk increased as depression symptoms increased. Another prospective cohort study with 29 years of follow-up data also showed that reporting five or more depression symptoms at baseline was associated with a $66 \%$ relative increase in stroke mortality, even when other stroke risk factors and change in depression status and other risk factors over time were included in the models. ${ }^{29}$

\section{POSSIBLE MECHANISMS LINKING DEPRESSIVE SYMPTOMS AND VASCULAR RISK}

Along with these intriguing epidemiological studies, other interesting pathophysiological data are also emerging related to possible mechanisms of the increased vascular risk in patients with depression. Possible vascular-specific mechanisms linking depressive symptoms and increased vascular risk include serotonin-mediated effects on platelets and increased inflammation (interleukin [IL]-6 and IL-1 $\beta$ influence depression risk and also stroke risk, possibly via enhanced atherosclerosis). It is not yet clear, however, whether these mechanisms are also related to added vascular risk in patients with PSD. Surface expression of platelet glycoprotein GPIb has been shown to be reduced in stroke patients and in those with depression alone, compared with healthy controls, but no additional reduction was observed in those with both stroke and depression. These data suggest that platelet dysfunction may possibly underlie the observed relationship between depression and increased vascular risk. ${ }^{30}$ Another study found that the number of platelet serotonin transporters was low in stroke patients compared with controls, which could theoretically lead to increased platelet aggregation and elevated risk of vascular events. ${ }^{31}$ Interestingly, the number of platelet serotonin transporters was not associated with the development of PSD. A possible genetic link between increased risk of depression and increased vascular events has also recently been proposed. ${ }^{32}$ This theory suggests that the serotonin gene functional polymorphism may be linked both to increased risk of depression and increased risk of vascular events. Other lines of evidence in this potential relationship come from treatment trials. One study found that in patients with depression after MI, selective serotonin reuptake inhibitor (SSRI) treatment was associated with decreased platelet activation, even in those patients already taking an antiplatelet medication, suggesting a potential mechanism for a reduction in cardiovascular events in depressed patients treated with SSRIs after MI. ${ }^{33}$ Another interesting supporting piece of evidence for this mechanism in MI patients is the observation that cognitive behavioral therapy improved depression in post-MI patients but did not reduce subsequent cardiac events, while antidepressant treatment was associated with significantly lower mortality or nonfatal myocardial infarction. ${ }^{34}$ Further studies in this area should help clarify whether depression-related disruptions in serotonin and subsequent platelet effects are at least partially related to the relationship between depression and vascular events.

In addition to platelet effects, behavioral factors such as impaired self-management, limited physical activity, impaired social roles and relationships, less collaborative care with providers, and decreased compliance also likely underlie the relationship between depression and vascular disease and may account for the worse outcomes seen in patients with depression in combination with many other medical conditions. ${ }^{35-39}$ For example, a longitudinal study of Hispanic subjects found that depressive symptoms were synergistic with diabetes and associated with worse diabetes control and increased micro- and macrovascular complications, even when controlling for multiple sociodemographic characteristics. ${ }^{35}$

Another possible mechanism linking depression and vascular disease is that depressive symptoms may influence the development of other vascular risk factors. Data from the NHANES I Epidemiology Follow-up Study demonstrated in up to 22 years of follow-up that negative affect at baseline was associated with the development of hypertension over time, even when adjusting for baseline blood pressure and other demographic and vascular risk factors. ${ }^{40}$ This relationship has been observed in other prospective cohort studies of young adults as well. ${ }^{41}$

\section{PSD EPIDEMIOLOGY}

Although methodological differences in study cohorts and methods of depression detection make pooling study results difficult, cumulative evidence indicates that 25 to $40 \%$ of stroke patients suffer from PSD, equally divided between major depression and other depressive disorders. ${ }^{42-54}$ Importantly, these data come from both practice-based cohorts and population-based studies (Table 3). Foundational work in PSD was done in the 1980s by Robinson and colleagues. ${ }^{50,51,53}$ Among their many important contributions were the findings that: (1) the prevalence of DSM-based diagnosis of PSD is at least 30\%, (2) PSD usually develops soon after stroke, (3) PSD usually persists throughout the first 6 to 12 months poststroke and often up to 2 years, and (4) PSD is associated with less neurological recovery after stroke. A limitation of this work is the select nature of the population (predominantly hospitalized AfricanAmerican males). Further, this study was conducted in the early 1980s, before the widespread availability of SSRI and other less toxic antidepressants, and few of the patients with PSD received treatment. Several community-based serial studies have also demonstrated that PSD is frequent, persistent, and undertreated. ${ }^{42-45,47,49,52,54}$ 
Table 3 Summary of PSD Prevalence Estimates

\begin{tabular}{|c|c|c|c|c|}
\hline Study & $n$ & Depression Assessment & Time Poststroke & Prevalence \\
\hline Andersen et $\mathrm{al}^{42}$ & 285 & HDRS & 1 year & $41 \%$ \\
\hline Astrom et $\mathrm{al}^{43}$ & 80 & DSM-III & 3 years & $16 \%$ (12 months); $31 \%$ (3 months) \\
\hline Burvill et al ${ }^{44}$ & 294 & DSM-III & 4 months & $23 \%$ \\
\hline Fuh et $\mathrm{al}^{45}$ & 45 & GDS & Variable & $\begin{array}{l}62 \% \text { (compared with } 33 \% \text { of } 1,471 \text { nonstroke } \\
\text { subjects) }\end{array}$ \\
\hline Herman et al ${ }^{47}$ & 150 & MADRS and Zung SDS & 1 year & $22-27 \%$ (3 months); $21-22 \%$ (1 year) \\
\hline Kotila et $\mathrm{al}^{49}$ & 423 & $\mathrm{BDI}$ & 1 year & 47\% (3 months); 47\% (1 year) \\
\hline Robinson et $\mathrm{al}^{50}$ & 103 & DSM-III & 6 months & $47 \%$ \\
\hline Pohjasvaara et al ${ }^{52}$ & 277 & DSM-III-R & 4 months & $40 \%$ \\
\hline Toso et $a^{54}$ & 1064 & BDI, MADRS, DSM-IV & 6 months & $34 \%$ \\
\hline
\end{tabular}

HDRS, Hamilton Depression Rating Scale; DSM, Diagnostic and Statistical Manual; GDS, Geriatric Depression Scale; MADRS, MontgomeryAsberg Depression Rating Scale; Zung SDS, Zung Self-rating Depression Scale; BDI, Beck Depression Inventory.

A multicenter study in Italy demonstrated DSM-based depression diagnoses in $34 \%$ of stroke survivors. ${ }^{54}$ The Helsinki Stroke Memory Aging Study ${ }^{52}$ reported a prevalence of $40 \%$ for any depressive disorder and $26 \%$ for major depression at 3 to 4 months post-ischemic stroke; 39\% were receiving antidepressant therapy. The FINNSTROKE Study ${ }^{49}$ evaluated 321 patients at 3 months poststroke and 311 patients at 12 months and found a depression prevalence of $47 \%$ at both time points. Only $17 \%$ were undergoing antidepressant drug therapy at 12 months. The Sunnybrook Stroke Study ${ }^{47}$ evaluated 150 patients at 3 months and 136 at 12 months and found a prevalence of "marked depressive symptoms" of $27 \%$ and $22 \%$ at these two time points. Fewer than $25 \%$ of depressed patients received antidepressants, and $70 \%$ of those depressed at 3 months remained so at 1 year. The Perth Community Stroke Study ${ }^{44}$ evaluated 294 patients at 4 months poststroke and found a PSD prevalence of $23 \%$. There were no differences between first-ever and recurrent strokes. At 12 months poststroke, $59 \%$ of the men and $30 \%$ of the women were still depressed. For those studies that identified major and minor depression it was not apparent that the prognosis differed by type of depressive disorder. The hospital-based studies typically report a higher prevalence of PSD ( $40 \%$ or greater), whereas the communitybased studies report prevalences of 20 to $40 \%$. By not assessing patients until 3 to 4 months poststroke, however, most of these community-based studies were not able to assess the prevalence and persistence of earlyonset depression and, in particular, its impact on functional recovery and stroke-specific health-related quality of life (HRQOL) during the critical months immediately poststroke.

\section{PSD IMPACTS MANY HEALTH OUTCOMES}

PSD is not only common but is also linked to worse outcome in both patients and caregivers after ischemic stroke. Just as depression in general has been associated with poorer functional outcome in a variety of conditions, ${ }^{58-63}$ PSD has similarly been linked to worse functional outcome and increased mortality after stroke, even when controlling for other variables. Specifically, depressed patients have been found to have greater impairments at various time points poststroke in activities of daily living. ${ }^{58-63}$ This negative effect of PSD was present even after depression remitted ${ }^{59}$ and was associated with deterioration in function over time. ${ }^{58,60}$ Morris and colleagues also demonstrated that patients with either major or minor depression poststroke were 3.4 times more likely to die during 10-year follow-up, and this risk was even higher in those socially isolated. ${ }^{64}$ More recently, data from a nationwide sample of veterans with ischemic stroke who survived at least 30 days poststroke showed that 3-year mortality was increased $25 \%$ in those with a new poststroke depression diagnosis compared with those without depression. ${ }^{65}$ Finally, there is growing evidence that PSD increases subsequent health care utilization. This relationship has been shown in other conditions, ${ }^{66-68}$ but a recent analysis of a national cohort of veterans with ischemic stroke showed that those with depression (and to a lesser extent those with other mental health conditions) poststroke had greater utilization of outpatient health care services and more inpatient admissions, even controlling for other chronic conditions and when mental health outpatient visits were omitted from the analyses. ${ }^{69}$

\section{IMPACT ON STROKE CAREGIVERS}

Family caregivers of stroke patients are impacted not only by the stroke itself but also patient PSD. Stroke caregivers in general have higher rates of depression, ${ }^{70-74}$ more physical symptoms, ${ }^{70,74}$ and higher levels of emotional distress ${ }^{70,72-74}$ than caregivers of nonstroke patients. Caregivers of patients with PSD may also be more likely to be depressed themselves. ${ }^{73}$ Other factors 
that may influence caregiver strain include amount of time spent helping the patient and caregiver health status. ${ }^{75,76}$ Caregivers of aphasic patients may be especially likely to experience greater distress and report higher burden. ${ }^{77}$ The importance of understanding the complex relationships between caregiver and patient outcomes is increasingly realized, ${ }^{78,79}$ as family caregivers play a large role in patient self-management of chronic conditions and in symptom recognition and compliance with treatment.

\section{RISK FACTORS FOR DEVELOPING PSD}

Many reports have addressed the question of what specific factors are related to the development of PSD. As with other studies of PSD, the generalizability of these studies are often hampered by selection bias, method of detecting depression, and time frame of assessment. Nonetheless, some reasonably consistent factors emerge as likely risk factors for the development of PSD.

\section{Lesion Location}

One of the most studied and debated issues in the field of stroke and depression research is whether specific stroke locations are associated with increased risk of developing depression. This possible explanation for the development of PSD has been attractive to neuroanatomists and neurophysiologists, because theoretically PSD might be more likely to develop after lesions that disrupt central nervous system (CNS) serotonin or norepinephrine pathways. In various analyses, Robinson and colleagues found that left hemisphere lesions, lesions in the right basal ganglia, and lesions closer to the frontal pole were associated with increased risk of developing PSD. ${ }^{80,81}$ Another study reported that lesions affecting the pallidum were associated with an increased risk of depression diagnosis 3 months after stroke and that lesion size was also associated with depression risk. ${ }^{82}$ Although a well-conducted systematic review of the existing literature did not support the association between any specific lesion location and the development of $\mathrm{PSD}^{83}$ and population-based studies have generally not found an association between lesion location and PSD, another meta-analysis by Narushima and colleagues did support the relationship of proximity to the frontal pole and PSD risk. ${ }^{84}$ One of the difficulties in studying this area, and specifically in conducting meta-analyses, is that a large proportion of the articles on this topic come from overlapping cohorts studied by Robinson and colleagues and thus do not represent independent findings in distinct stroke patients. As new neuroimaging techniques emerge, this issue and the issue of whether lesion location is related to treatment response will likely continue to be studied and debated but, at present, lesion location should not be used as a variable to determine which stroke patients should be screened for PSD.

\section{Stroke Severity}

Many studies have examined the issue of whether persons with more severe stroke are more likely to develop PSD. This can be a complicated issue to examine because these patients are also more likely to have communication and/or cognitive effects of stroke that make depression assessment difficult and because the relationship between stroke severity and depression may be somewhat bidirectional. Stroke survivors with more severe stroke impairments may be more likely to develop depression, but there is also strong evidence that depression after stroke negatively impacts recovery, so crosssectional studies that do not take into account stroke deficits at the time of stroke onset may reveal only a part of this relationship.

Although the precise relationship may not always be determined and some studies do not report this association, ${ }^{85,86}$ multiple studies have found that increased stroke impairment and/or functional dependence are related to PSD at various time points. ${ }^{87-89}$ Both Robinson and colleagues ${ }^{90}$ and Astrom and associates ${ }^{43}$ reported that the relationship between depression and poststroke impairment is dynamic: the strength of their association increased during the first 6 months poststroke and then decreased. Robinson has speculated that reasons for this time-dependent relationship may include: (1) the most impaired patients either are more likely to remain depressed or have worsened depression symptoms over time, (2) depressed patients may have less recovery in function, or (3) other factors influence both depression and impairments/functional recovery poststroke. $^{91}$

\section{Other PSD Risk Factors}

Many other factors have also been reported to be associated with increased risk of developing PSD, although again the temporal relationship of these variables is not always clearly evaluated. In addition to lesion location, factors purported to increase risk of developing PSD include: female gender, increasing age, lack of social support, cognitive dysfunction, and prestroke history of depression. One literature synthesis has suggested that the factors most consistently associated with PSD are past history of depression, past personal psychiatric history, dysphasia, functional impairments, living alone, and poststroke social isolation. ${ }^{92}$ Differences in study cohorts and measurement of key variables make it difficult to draw widely generalizable conclusions from these data, and so screening of all patients regardless of PSD risk factors seems most appropriate from a clinical standpoint. 


\section{SUICIDALITY IN PATIENTS WITH PSD}

Because the incidence of successful suicide increases with age, it is important to address the issue of suicidality in stroke survivors. Several reports suggest that suicide rates are increased in stroke survivors, with at least two of these being well-designed population-based cohorts in Denmark in which the risk of suicide was almost twice as high in stroke patients compared with other agematched persons without stroke. ${ }^{93,94}$ Factors in addition to depression symptoms that may be related to this risk include prior history of stroke and increased disability. ${ }^{95}$ Many more patients likely have suicidal ideation but do not act on these thoughts: one study reported that $7 \%$ of adults with acute medical illnesses (including stroke) had clinically significant suicidal ideation during up to 24 months after the acute event. ${ }^{96}$ In our National Institutes of Health (NIH)-funded case management trial in PSD patients, we found that $\sim 10 \%$ of stroke survivors endorse "thoughts of death or harming yourself" (item nine from the $\mathrm{PHQ}-9$ ), but with standardized probe questions, almost all of these represent passive thoughts of death rather than active suicidal ideation (unpublished data). Nonetheless, given the persistent reports of elevated suicide risk in population-based cohorts, these data are another piece of evidence supporting the routine screening for depression in all stroke survivors.

\section{TREATMENT OF DEPRESSION IN STROKE SURVIVORS}

Despite the long and extensive history of investigation into the epidemiology and consequences of PSD, surprisingly few well-conducted studies have been done of sufficient size to address critical PSD treatment questions. In general, studies of PSD treatment can be divided into two themes: antidepressants to prevent PSD and antidepressants as treatment of PSD. Recently, Cochrane reviews of antidepressant treatment have been completed for both of these key questions. ${ }^{97,98}$ Although both of these reviews conclude that evidence is insufficient to recommend treatment specifically for preventing or treating depression in stroke patients, it would seem overly simplistic and nihilistic to therefore conclude that depression in patients who have had a stroke should therefore remain untreated. This is especially the case as the majority of PSD treatment studies that have been conducted have been small, many have not used rigorous clinical trial methodology, and most trials have demonstrated reduction of depression symptoms in patients on treatment, if not complete remission of depression. Rather, the overwhelming evidence for treating depression, regardless of what other medical conditions coexist, should at present be sufficient for providers to confidently treat depression symptoms in stroke patients. Future trials, like our ongoing National Institute for Neurologic Disorders and Stroke (NINDS)-funded study of depression case management versus usual care in patients with PSD, will help inform this issue.

To provide help with interpreting the PSD treatment literature, Table 4 details published randomized, blinded, trials of PSD treatment. ${ }^{99-106}$ The majority of these studies have tested SSRIs, but a few have used other classes of antidepressant medications. Some trials included only ischemic stroke patients but others included those with hemorrhagic stroke types as well. In general, most studies have demonstrated significant improvements in depression symptoms but not always in complete remission of depression. Whether this reduction in symptoms is clinically meaningful to patients' quality of life and whether treatment of depression affects rate or trajectory of recovery remain important unanswered questions.

Some studies have attempted to compare different antidepressants, but the small sample size raises the question of what difference the study would actually be powered to see. One of these found that citalopram and reboxetine had similar efficacy and low side effect profiles, but that citalopram was more effective in depression with anxiety and reboxetine was more effective in depression with psychomotor retardation. ${ }^{107}$ Another study reported that nortriptyline was superior to fluoxetine in efficacy and side effect profile, but this was a very small study with a complicated crossover design and high dropout rate, so conclusions were based on less than 20 participants in each study arm and are thus difficult to interpret. ${ }^{103}$

\section{PREVENTING PSD}

Relatively little evidence exists to suggest that treatment of stroke patients to prevent the development of PSD is beneficial, although strategies to address this hypothesis in patients at especially high risk of developing PSD have not been tested. One of the largest prevention trials to date randomized 137 patients to treatment with sertraline versus placebo for 12 weeks. ${ }^{108}$ Among treated subjects, $13 / 70$ developed depression by the end of the treatment period, compared with $20 / 67$ in the control group $(P=<0.05)$. Another study randomized 100 stroke patients to the SSRI mianserin versus placebo for 1 year after stroke regardless of depressive symptoms. ${ }^{109}$ Early treatment with antidepressants did not prevent PSD, likely due to the high dropout rate (only 64 patients had 12-month outcome assessment) and small sample size. Another small study did show significant benefit for preventing depression, with 2 of 35 mirtazipine-treated patients developing depression compared with 14 of 35 control patients $(P=<0.05) .^{110}$ Finally, a small randomized, placebo-controlled trial of fluoxetine $20 \mathrm{mg}$ within 2 weeks of stroke onset did not reduce depression symptoms compared with placebo at 4 weeks but was associated with reduced depression 
Table 4 Randomized, Placebo-Controlled Clinical Trials of Antidepressants for Treatment of PSD

\begin{tabular}{|c|c|c|c|}
\hline Study & Drug, Duration & Drug vs Placebo & Results \\
\hline Lipsey et al ${ }^{99}$ & Nortriptyline, 6 weeks & 17 vs 22 & $\begin{array}{l}\text { HAM-D improved } 11.5 \text { points ( } 14 \text { to } 2.5) \text { in drug } \\
\text { group vs } 7 \text { (16.5 to } 9.5 \text { ) in placebo group }(P=0.0006) \\
\text { Zung depression score improved } 18 \text { vs } 12 \text { points }(P=0.03)\end{array}$ \\
\hline Reding et $\mathrm{al}^{100}$ & Trazodone, $\sim 4$ weeks & 27 total & $\begin{array}{l}\text { Randomized } 27 \text { admitted inpatients in stroke rehabilitation to } \\
\text { trazodone vs placebo, whether or not they were depressed } \\
\text { Improved Zung scores in the subgroup of } 16 \text { patients who had } \\
\text { a positive DST }\end{array}$ \\
\hline Andersen et al ${ }^{102}$ & Citalopram, 6 weeks & 33 vs 33 & $\begin{array}{l}\text { HAM-D improved } 8 \text { (19.4 to } 11.4) \text { in drug group vs } 4.8 \text { (18.9 to } \\
\text { 14.1) in placebo group }(P<0.05) \\
\text { In the } 59 \text { completers, HAM-D more likely to fall } \geq 50 \% \text { in drug } \\
\text { than in placebo group ( } 59 \% \text { vs } 28 \%, P<0.05)\end{array}$ \\
\hline Fruehwald et al ${ }^{106}$ & Fluoxetine, 12 weeks & 26 vs 24 & $\begin{array}{l}\text { HAM-D improved in } 8 \text { of treatment group compared with } 6 \text { of } \\
\text { placebo group }(P>0.05)\end{array}$ \\
\hline Murray et $\mathrm{al}^{105}$ & Sertraline, 26 weeks & 62 vs 61 & $\begin{array}{l}31 \text { in treatment group compared with } 34 \text { in placebo group } \\
\quad(P>0.05)\end{array}$ \\
\hline Wiart et al $^{104}$ & Fluoxetine, 6 weeks & 16 vs 15 & $\begin{array}{l}\text { MADRS decreased in } 16.7 \text { in treatment group compared with } \\
8.5 \text { in placebo group }(P<0.05)\end{array}$ \\
\hline Ohtomo et al ${ }^{101}$ & Aniracetam, 12 weeks & 108 vs 65 & $\begin{array}{l}\text { Clinician impression of no depression at end of treatment in } 52 \\
\text { of treatment group compared with } 32 \text { in placebo group } \\
(P>0.05)\end{array}$ \\
\hline Robinson et al ${ }^{103}$ & $\begin{array}{l}\text { Fluoxetine, nortriptyline, } \\
12 \text { weeks }\end{array}$ & 23 vs 16 vs 17 & $\begin{array}{l}\text { Successful treatment in 10/16 nortriptyline, 2/23 fluoxetine, } \\
\text { and } 4 / 17 \text { placebo patients } \\
\text { Significantly lower HAM-D scores in nortriptyline group (9.0) } \\
\text { and placebo group (12.2) than fluoxetine group (18.5) }\end{array}$ \\
\hline
\end{tabular}

HAM-D, Hamilton Depression Inventory; MADRS, Montgomery-Asberg Depression Rating Scale.

symptoms at 12 weeks and 18 months. This suggested a relatively high rate of spontaneous remission of early depression symptoms, but also demonstrates potential intermediate and long-term benefit of antidepressant treatment in patients with depression after stroke. ${ }^{111}$

Regardless of whether they are used for prevention or treatment of PSD, even less is known about other classes of medications and nonpharmacological depression treatments, including psychostimulants, ${ }^{112,113}$ tricyclic antidepressants, ${ }^{114,115}$ and buspirone. ${ }^{116}$ Other studies have included short-term non-placebocontrolled trials ${ }^{117}$ or open trials of antidepressants and placebo. ${ }^{118,119}$ There are even fewer studies of nonpharmacological treatments, like psychotherapy ${ }^{120}$ or electroconvulsive therapy, for PSD. ${ }^{121}$ However, two recent studies suggest a possible role for nonpharmacological treatments in reducing anxiety poststroke. In one of these, a supportive program (three telephone calls and one home visit) after stroke did not reduce depression symptoms at 6 months poststroke compared with usual care, but did reduce anxiety and improve subjects' SF-36 Role-Emotional scores. ${ }^{122}$ Another study reported that an educational program reduced patient anxiety (not depression) at 6 months compared with usual care. ${ }^{123}$ Further studies of this type, employing proven depression treatments like cognitive behavioral therapy and using proven delivery models like telephone-based counseling and collaborative care, should be undertaken in stroke survivors. ${ }^{124}$

Not surprisingly, in light of the relatively meager amount of high-quality treatment evidence, many important questions remain unanswered. Although the notion that PSD is undertreated is generally supported by the community-based studies and by surveys in the United States, undertreatment of PSD was not found in a recent Swedish national survey. ${ }^{125}$ In this self-report survey, $14 \%$ of stroke survivors had depressive symptoms and $25 \%$ of those with stroke were taking an antidepressant. However, $8 \%$ of those reporting depressive symptoms were not treated. Stroke survivors were significantly more likely to be taking an antidepressant than those without stroke. As antidepressant use has become more convenient and better accepted culturally, and medications with less side effects have become available, it may be that more patients will be treated. Conversely, recent negative press about antidepressants, particularly SSRIs, and suicide risk in children may reduce providers' willingness to treat and patients' acceptance of treatment.

Another critical question that is still largely unanswered is whether treatment of PSD reduces mortality risk. One study that has shed some light on this is 
the trial of fluoxetine, nortriptyline, and placebo for 12 weeks in the first 6 months poststroke. ${ }^{126}$ During 9 years of follow-up, those patients who completed the full dose of antidepressant therapy $(n=53)$ had significantly lower mortality than those receiving placebo for 12 weeks $(n=28)$. However, the relatively high number of "noncompleters" $(n=23)$ and their relationship to the analysis in this report make it somewhat difficult to draw firm conclusions regarding the data. For example, perhaps other unmeasured characteristics that differed between completers and noncompleters in the study are associated with subsequent mortality risk. Other questions that need further study include: (1) Does the improvement in depression symptoms translate to remission of depression diagnosis and to improved quality of life in stroke survivors? (2) Do early symptoms of PSD (i.e., in the first 1 to 2 months) need to be treated, or does PSD during this time period often spontaneously improve? (3) Does treatment of PSD influence stroke recovery? (4) If patients are not depressed soon after stroke, how likely are they to become depressed later? (5) Do symptoms of emotionality immediately after stroke predict the likelihood of subsequent depression? One recent small study suggested that the early initiation of antidepressants in patients with PSD may be important. In this study $(n=62)$, those who received antidepressant treatment within 1 month poststroke had less functional impairment at 3 months and at 2 years poststroke compared with those who received antidepressants after 1 month poststroke. ${ }^{127}$

\section{WHO SHOULD DIAGNOSE AND TREAT PSD?}

Although neurologists may or may not elect to manage depression in their patients, in some patients with chronic progressive neurological disease the neurologist may in effect be a primary care provider. Thus, knowing the current best practices in depression assessment, treatment, and care delivery in primary care may be beneficial. Stroke patients have complicated post-acute outpatient needs, including review of diagnostic tests, adjustment of medications to treat stroke risk factors, assessment of rehabilitation needs, and symptom management. These competing patient and provider demands can make depression detection difficult. In some managed care settings, including the Veterans Health Administration (VHA), annual depression screening for all patients in primary care is a performance measure. Because almost one third of patients screen positive for depression at their first neurology clinic visit, neurologists may also want to adopt a brief, self-completed depression screening tool like the PHQ-9 in their outpatient clinic materials. ${ }^{128}$ In addition to initiating an antidepressant, key components of quality depression care include a follow-up visit within 6 weeks of initial diagnosis and maintenance of antidepressant therapy for at least 6 months. One care model that can help ensure adequate follow-up and promote adherence to medication management is telephone-based psychotherapy and care management. ${ }^{124,129}$ At the very least, neurologists should consider screening all stroke patients for depression in the first few months poststroke, and then either initiating treatment or ensuring prompt communication with primary care providers to initiate and monitor treatment.

\section{FUTURE DIRECTIONS/CONCLUSION}

Much work remains to be done to better understand the reasons why stroke survivors develop depression, to predict what treatments are most likely to be efficacious in ameliorating or preventing depression, and to understand how depression influences stroke recovery across the spectrum of behavioral, anatomical, chemical, and genetic mediators. Likewise, much work also remains to be done to ensure that patients and providers recognize the symptoms of depression after stroke and that patients receive and accept best practices in treating depression.

\section{REFERENCES}

1. Gordon WA, Hibbard MR. Poststroke depression: an examination of the literature. Arch Phys Med Rehabil 1997;78:658-663

2. Gordon WA, Hibbard MR, Egelko S, et al. Issues in the diagnosis of post-stroke depression. Rehabil Psychol 1991; 36:71-87

3. Starkstein SE, Robinson RG. Affective disorders and cerebral vascular disease. Br J Psychiatry 1989;154:170-182

4. Black KJ. Diagnosing depression after stroke. South Med J 1995;88:699-708

5. Paradiso S, Ohkubo T, Robinson RG. Vegetative and psychological symptoms associated with depressed mood over the first two years after stroke. Int J Psychiatry Med 1997;27:137-157

6. Mosnik D, Williams LS, Kroenke K, Callahan C. Symptoms of post-stroke depression: a distinct syndrome compared to geriatric depression [abstract]. Neurology 2000;54(suppl 3): A378-A379

7. Williams LS, Brizendine EJ, Plue L, et al. Performance of the PHQ-9 as a screening tool for post-stroke depression. Stroke 2005;36:635-638

8. Morris PL, Robinson RG, Raphael B. Emotional lability after stroke. Aust NZJ Psychiatry 1993;27:601-605

9. Calvert T, Knapp P, House A. Psychological associations with emotionalism after stroke. J Neurol Neurosurg Psychiatry 1998;65:928-929

10. Bogousslavsky J. William Feinberg lecture 2002: emotions, mood, and behavior after stroke. Stroke 2003;34:1046-1050

11. Johnson G, Burvill PW, Anderson CS, Jamrozik K, StewartWynne EG, Chakera TM. Screening instruments for depression and anxiety following stroke: experience in the Perth Community Stroke Study. Acta Psychiatr Scand 1995;91: 252-257 
12. Gainotti G, Azzoni A, Razzano C, Lanzillotta M, Marra C, Gasparini F. The Post-Stroke Depression Rating Scale: a test specifically devised to investigate affective disorders of stroke patients. J Clin Exp Neuropsychol 1997;19:340356

13. O’Rourke S, MacHale S, Signorini D, Dennis M. Detecting psychiatric morbidity after stroke: comparison of the GHQ and the HAD Scale. Stroke 1998;29:980-985

14. Aben I, Verhey F, Lousberg R, Lodder J, Honig A. Validity of the Beck depression inventory, hospital anxiety and depression scale, SCL-90, and Hamilton depression rating scale as screening instruments for depression in stroke patients. Psychosomatics 2002;43:386-393

15. Lincoln NB, Nicholl CR, Flannaghan T, Leonard M, Van der Gucht E. The validity of questionnaire measures for assessing depression after stroke. Clin Rehabil 2003;17:840846

16. Spitzer RL, Kroenke K, Williams JBW. Patient Health Questionnaire Study Group. Validity and utility of a selfreport version of PRIME-MD: the PHQ Primary Care Study. JAMA 1999;282:1737-1744

17. Kroenke K, Spitzer RL, Williams JBW. The PHQ-9: validity of a brief depression severity measure. J Gen Intern Med 2001;16:606-613

18. Davies SJC, Jackson PR, Potokar J, Nutt DJ. Treatment of anxiety and depressive disorders in patients with cardiovascular disease. BMJ 2004;328:939-943

19. Whyte EM, Mulsant BH, Vanderbilt J, Dodge HH, Ganguli M. Depression after stroke: a prospective epidemiological study. J Am Geriatr Soc 2004;52:774-778

20. Ostir GV, Markides KS, Peek MK, Goodwin JS. The association between emotional well-being and the incidence of stroke in older adults. Psychosom Med 2001;63:210215

21. Ostir GV, Goodwin JS, Markides KS, Ottenbacher KJ, Balfour J, Guralnik JM. Differential effects of premorbid physical and emotional health on recovery from acute events. J Am Geriatr Soc 2002;50:713-718

22. Jonas BS, Mussolino ME. Symptoms of depression as a prospective risk factor for stroke. Psychosom Med 2000;62: 463-471

23. Ohira T, Iso H, Satoh S, et al. Prospective study of depressive symptoms and risk of stroke among Japanese. Stroke 2001;32:903-908

24. Nilsson FM, Kessing LV. Increased risk of developing stroke for patients with major affective disorder: a registry study. Eur Arch Psychiatry Clin Neurosci 2004;254:387-391

25. Lyness JM. The cerebrovascular model of depression in late life. CNS Spectr 2002;7:712-715

26. Mast BT, MacNeill SE, Lichtenberg PA. Post-stroke and clinically-defined vascular depression in geriatric rehabilitation patients. Am J Geriatr Psychiatry 2004;12:84-92

27. Thomas AJ, Kalaria RN, O’Brien JT. Depression and vascular disease: what is the relationship? J Affect Disord 2004;79:81-95

28. Gump BB, Matthews KA, Eberly LE, Chang YF. Depressive symptoms and mortality in men: results from the Multiple Risk Factor Intervention Trial. Stroke 2005;36:98102

29. Everson SA, Roberts RE, Goldberg DE, Kaplan GA. Depressive symptoms and increased risk of stroke mortality over a 29-year period. Arch Intern Med 1998;158:11331138
30. Cassidy EM, Walsh MT, O'Connor R, et al. Platelet surface glycoprotein expression in post-stroke depression: a preliminary study. Psychiatry Res 2003;118:175-181

31. Rasmussen A, Christensen J, Clemmensen PM, et al. Platelet serotonin transporter in stroke patients. Acta Neurol Scand 2003;107:150-153

32. Ramasubbu R. Serotonin transporter gene functional polymorphism: a plausible candidate gene for increased vascular risk in depression. Med Hypotheses 2003;61:36-44

33. Serebruany VL, Glassman AH, Malinin AI, et al. Platelet/ endothelial biomarkers in depressed patients treated with the selective serotonin reuptake inhibitor sertraline after acute coronary events: the Sertraline AntiDepressant Heart Attach Randomized Trial (SADHART) Platelet Substudy. Circulation 2003;108:939-944

34. Berkman LF, Blumenthal J, Burg M, et al. Effects of treating depression and low perceived social support on clinical events after myocardial infarction: the Enhancing Recovery in Coronary Heart Disease Patients (ENRICHD) Randomized Trial. JAMA 2003;289:3106-3116

35. Black SA, Markides KS, Ray LA. Depression predicts increased incidence of adverse health outcomes in older Mexican Americans with type 2 diabetes. Diabetes Care 2003;26:2822-2828

36. Kiecolt-Glaser JK, McGuire L, Robles TF, Glaser R. Emotions, morbidity, and mortality: new perspectives from psychoneuroimmunology. Annu Rev Psychol 2002;53:83107

37. Penninx BW, van Tilburg T, Kriegsman DM, Deeg DJ, Boeke AJ, van Eijk JT. Effects of social support and personal coping resources on mortality in older age: the Longitudinal Aging Study Amsterdam. Am J Epidemiol 1997;146:510 519

38. Licinio J, Wong ML. The role of inflammatory mediators in the biology of major depression: central nervous system cytokines modulate the biological substrate of depressive symptoms, regulate stress-responsive systems, and contribute to neurotoxicity and neuroprotection. Mol Psychiatry 1999; 4:317-327

39. Morey MC, Pieper CF, Crowley GM, Sullivan RJ, Publisi CM. Exercise adherence and 10-year mortality in chronically ill older adults. J Am Geriatr Soc 2002;50:1929-1933

40. Jonas BS, Lando JF. Negative affect as a prospective risk factor for hypertension. Psychosom Med 2000;62:188-196

41. Davidson K, Jonas BS, Dixon KE, Markovitz JH. Do depression symptoms predict early hypertension incidence in young adults in the CARDIA study? Coronary Artery Risk Development in Young Adults. Arch Intern Med 2000;160: 1495-1500

42. Andersen G, Vestergaard K, Riis JO, Lauritzen L. Incidence of poststroke depression during the first year in a large unselected stroke population determined using a valid standardized rating scale. Acta Psychiatr Scand 1994;90:190-195

43. Astrom M, Adolfsson R, Asplund K. Major depression in stroke patients: a 3-year longitudinal study. Stroke 1993;24: 976-982

44. Burvill PW, Johnson GA, Jamrozik KD, Anderson CS, Stewart-Wynne EG, Chakera TM. Prevalence of depression after stroke: the Perth Community Stroke Study. Br J Psychiatry 1995;166:320-327

45. Fuh JL, Liu HC, Wang SJ, Liu CY, Wang PN. Poststroke depression among the Chinese elderly in a rural community. Stroke 1997;28:1126-1129 
46. Ghika-Schmid F, Bogousslavsky J. Affective disorders following stroke. Eur Neurol 1997;38:75-81

47. Herrmann N, Black SE, Lawrence J, Szekely C, Szalai JP. The Sunnybrook Stroke Study: a prospective study of depressive symptoms and functional outcomes. Stroke 1998;29: 618-624

48. House A, Dennis M, Warlow C, Hawton K, Molyneux A. Mood disorders after stroke and their relation to lesion location: a CT scan study. Brain 1990;113:1113-1129

49. Kotila M, Numminen H, Waltimo O, Kaste M. Depression after stroke: results of the FINNSTROKE study. Stroke 1998;29:368-372

50. Robinson RG, Price TR. Post-stroke depressive disorders: a follow-up study of 103 patients. Stroke 1982;13:635-641

51. Robinson RG, Starr LB, Price TR. A two year longitudinal study of mood disorders following stroke: prevalence and duration at six months follow-up. Br J Psychiatry 1984;144: 256-262

52. Pohjasvaara T, Leppavuori A, Siira I, Vataja R, Kaste M, Erkinjuntti T. Frequency and clinical determinants of poststroke depression. Stroke 1998;29:2311-2317

53. Robinson RG, Starr LB, Kubos KL, Price TR. A 2-year longitudinal study of post-stroke mood disorders: findings during the initial evaluation. Stroke 1983;14:736-741

54. Toso V, Gandolfo C, Paolucci S, Provinciali L, Torta R, Grassivaro N; DESTRO Study Group. Post-stroke depression: research methodology of a large multicentre observational study (DESTRO). Neurol Sci 2004;25:138-144

55. Spitzer RL, Kroenke K, Linzer M, et al. Health-related quality of life in primary care patients with mental disorders: results from the PRIME-MD 1000 study. JAMA 1995;274: 1511-1517

56. Hays RD, Wells KB, Sherbourne CD, Rogers W, Spritzer $\mathrm{K}$. Functioning and well-being outcomes of patients with depression compared with chronic general medical illness. Arch Gen Psychiatry 1995;52:11-19

57. Wells KB, Stewart A, Hays RD, et al. The functioning and well-being of depressed patients: results from the Medical Outcomes Study. JAMA 1989;262:914-919

58. Sinyor D, Amato P, Kaloupek DG, Becker R, Goldenberg M, Coopersmith H. Post-stroke depression: relationships to functional impairment, coping strategies and rehabilitation outcome. Stroke 1986;17:1102-1107

59. Parikh RM, Robinson RG, Lipsey JR, Starkstein SE, Fedoroff JP, Price TR. The impact of poststroke depression on recovery in activities of daily living over a 2 -year followup. Arch Neurol 1990;47:785-789

60. Morris PLP, Raphael B, Robinson RG. Clinical depression is associated with impaired recovery from stroke. Med J Aust 1992;157:239-242

61. Schubert DSP, Taylor C, Lee S, Mentari A, Tamaklo W. Physical consequences of depression in the stroke patient. Gen Hosp Psychiatry 1992;14:69-76

62. Ramasubbu R, Robinson RG, Flint AJ, Kosier T, Price TR Functional impairment associated with acute poststroke depression: the Stroke Data Bank Study. J Neuropsychiatry Clin Neurosci 1998;10:26-33

63. Kauhanen M, Korpelainen JT, Hiltunen P, et al. Poststroke depression correlates with cognitive impairment and neurological deficits. Stroke 1999;30:1875-1880

64. Morris PLP, Robinson RG, Andrzejewski P, Samules J, Price TR. Association of depression with 10-year poststroke mortality. Am J Psychiatry 1993;150:124-129
65. Williams LS, Ghose S, Swindle RW. The effect of depression and other mental health diagnoses on mortality after ischemic stroke. Am J Psychiatry 2004;161:1090-1095

66. Unutzer J, Patrick DL, Simon G, et al. Depressive symptoms and the cost of health services in HMO patients aged 65 years and older: a 4-year prospective study. JAMA 1997;277: 1618-1623

67. Druss BG, Rohrbaugh RM, Rosenheck R. Depressive symptoms and health costs in older medical patients. Am J Psychiatry 1999;156:477-479

68. Simon G, VonKorff M, Barlow M. Health care costs of primary care patients with recognized depression. Arch Gen Psychiatry 1995;52:850-856

69. Ghose S, Swindle R, Williams LS. Depression and other mental health diagnoses after stroke increase inpatient and outpatient medical utilization 3 years post-stroke. Am J Psychiatry 2004;161:1090-1095

70. Carnwath TCM, Johnson DAW. Psychiatric morbidity among spouses of patients with stroke. BMJ 1987;294:409411

71. Tompkins CA, Schulz R, Rau MT. Post-stroke depression in primary support persons: predicting those at risk. J Consult Clin Psychol 1988;56:502-508

72. Anderson CS, Linto J, Stewart-Wynne EG. A populationbased assessment of the impact and burden of caregiving for long-term stroke survivors. Stroke 1995;26:843-849

73. Dennis M, O'Rourke S, Lewis S, Sharpe M, Warlow C. A quantitative study of the emotional outcome of people caring for stroke survivors. Stroke 1998;29:1867-1872

74. Greveson GC, Gray CS, French JM, James OFW. Longterm outcome for patients and carers following hospital admission for stroke. Age Ageing 1991;20:337-344

75. Bugge C, Alexander H, Hagen S. Stroke patients' informal caregivers: patient, caregiver, and service factors that affect caregiver strain. Stroke 1999;30:1517-1523

76. Bakas T, Austin JK, Jessup SL, Williams LS, Oberst MT. Time and difficulty of tasks provided by family caregivers of stroke survivors. J Neurosci Nurs 2004;36:95-106

77. Bakas T, Kroenke K, Plue LD, Perkins S, Williams LS Outcomes among family caregivers of aphasic versus nonaphasic stroke survivors. Rehabil Nurs 2005. In press

78. Carter JH, Nutt JG. Family caregiving: a neglected and hidden part of health care delivery. Neurology 1998;51: $1245-1246$

79. Han B, Haley WE. Family caregiving for patients with stroke: review and analysis. Stroke 1999;30:1478-1485

80. Robinson RG, Kubos KL, Starr LB, Rao K, Price TR. Mood changes in stroke patients: importance of lesion location. Brain 1984;107:81-93

81. Robinson RG, Szetela B. Mood change following left hemispheric brain injury. Ann Neurol 1981;9:447-453

82. Vataja R, Leppavuori A, Pohjasvaara T, et al. Poststroke depression and lesion location revisited. J Neuropsychiatry Clin Neurosci 2004;16:156-162

83. Carson AJ, MacHale S, Allen K, et al. Depression after stroke and lesion location: a systematic review. Lancet 2000; 356:122-126

84. Narushima K, Kosier JT, Robinson RG. A reappraisal of poststroke depression, intra- and inter-hemispheric lesion location using meta-analysis. J Neuropsychiatry Clin Neurosci 2003;15:422-430

85. Cassidy E, O'Connor R, O'Keane V. Prevalence of poststroke depression in an Irish sample and its relationship with 
disability and outcome following inpatient rehabilitation. Disabil Rehabil 2004;26:71-77

86. Andersen G, Vestergaard K, Ingemann-Nielsen M, Lauritzen L. Risk factors for post-stroke depression. Acta Psychiatr Scand 1995;92:193-198

87. Naess H, Nyland HI, Thomassen L, Aarseth J, Myhr KM. Mild depression in young adults with cerebral infarction at long-term follow-up: a population-based study. Eur J Neurol 2005;12:194-198

88. Burvill P, Johnson G, Jamrozik K, Anderson C, StewartWynne E. Risk factors for post-stroke depression. Int J Geriatr Psychiatry 1997;12:219-226

89. Sharpe M, Hawton K, Seagroatt V, et al. Depressive disorders in long-term survivors of stroke: associates with demographic and social factors, functional status, and brain lesion volume. Br J Psychiatry 1994;164:380-386

90. Robinson RG, Starr LB, Lipsey JR, Rao K, Price TR. A two-year longitudinal study of post-stroke mood disorders: dynamic changes in associated variables over the first six months of follow-up. Stroke 1984;15:510-517

91. Robinson RG. Relationship of depression to physical impairment. In: Robinson RG, ed. The Clinical Neuropsychiatry of Stroke. Cambridge, UK: Cambridge University Press; 1998:141-149

92. Ouimet MA, Primeau F, Cole MG. Psychosocial risk factors in poststroke depression: a systematic review. Can J Psychiatry 2001;46:819-828

93. Teasdale TW, Engberg AW. Suicide after a stroke: a population study. J Epidemiol Community Health 2001;55: 863-866

94. Bronnum-Hansen $\mathrm{H}$, Davidsen $\mathrm{M}$, Thorvaldsen $\mathrm{P}$, for the Danish MONICA Study Group. Long-term survival and causes of death after stroke. Stroke 2001;32:21312136

95. Pohjasvaara T, Vataja R, Leppavuori A, Kaste M, Erkinjuntti T. Suicidal ideas in stroke patients 3 and 15 months after stroke. Cerebrovasc Dis 2001;12:21-26

96. Kishi Y, Robinson RG, Kosier JT. Suicidal ideation among patients with acute life-threatening physical illness: patients with stroke, traumatic brain injury, myocardial infarction, and spinal cord injury. Psychosomatics 2001;42:382-390

97. Anderson CS, Hackett ML, House AO. Interventions for preventing depression after stroke (Cochrane review). In: The Cochrane Library; Issue 2. Oxford: Update Software; 2004

98. Hackett ML, Anderson CS, House AO. Interventions for treating depression after stroke (Cochrane review). In: The Cochrane Library; Issue 3. Oxford: Update Software; 2004

99. Lipsey JR, Robinson RG, Pearlson GD, Rao K. Nortriptyline treatment of post-stroke depression: a double-blind study. Lancet 1984;1:297-300

100. Reding MJ, Orto LA, Winter SW, Fortuna IM, Di Ponte P, McDowell FH. Antidepressant therapy after stroke: a double-blind trial. Arch Neurol 1986;43:763-765

101. Ohtomo E, Hirai S, Terashi A, et al. Clinical evaluation of aniracetam on psychiatric symptoms related to cerebrovascular disease. J Clinical Experimental Medicine 1991;156: 143-187

102. Andersen G, Vestergaard K, Lauritzen L. Effective treatment of poststroke depression with the selective serotonin reuptake inhibitor citalopram. Stroke 1994;25: 1099-1104
103. Robinson RG, Schultz SK, Castillo C, et al. Nortriptyline versus fluoxetine in the treatment of depression and in shortterm recovery after stroke: a placebo-controlled, doubleblind study. Am J Psychiatry 2000;157:351-359

104. Wiart L, Petit H, Joseph PA, Mazaux JM, Barat M Fluoxetine in early poststroke depression: a double-blind placebo-controlled study. Stroke 2000;31:1829-1832

105. Murray V, von Arbin M, Bartfai A, et al. Double-blind comparison of sertraline and placebo in stroke patients with minor depression and less severe major depression. J Clin Psychiatry 2005;66:708-716

106. Fruehwald S, Gatterbauer E, Rehak P, Baumhackl U. Early fluoxetine treatment of post-stroke depression: a three-month double-blind placebo-controlled study with an open-label long-term follow up. J Neurol 2003;250:347351

107. Rampello L, Chiechio S, Nicoletti G, et al. Prediction of the response to citalopram and reboxetine in post-stroke depressed patients. Psychopharmacology (Berl) 2004;173: 73-78

108. Rasmussen A, Lunde M, Poulsen DL, Sorensen K, Ovitazau S, Bech P. A double-blind, placebo-controlled study of sertraline in the prevention of depression in stroke patients. Psychosomatics 2003;44:216-221

109. Palomaki H, Kaste M, Berg A, et al. Prevention of poststroke depression: 1 year randomized placebo controlled double blind trial of mianserin with 6 month follow up after therapy. J Neurol Neurosurg Psychiatry 1999;66:490-494

110. Niedermaier N, Bohrer E, Schulte K, Sclattmann P, Heuser I. Prevention and treatment of poststroke depression with mirtazapine in patients with acute stroke. J Clin Psychiatry 2004;65:1619-1623

111. Fruehwald S, Gatterbauer E, Rehak P, Baumhackl U. Early fluoxetine treatment of post-stroke depression: a threemonth double-blind placebo-controlled study with an openlabel long-term follow up. J Neurol 2003;250:347-351

112. Masand P, Murray GB, Pickett P. Psychostimulants in poststroke depression. J Neuropsychiatry Clin Neurosci 1991;3: 23-27

113. Lazarus LW, Winemiller DR, Lingam VR, et al. Efficacy and side effects of methylphenidate for poststroke depression. J Clin Psychiatry 1992;53:447-449

114. Shima S. The efficacy of antidepressants in post-stroke depression. Keio J Med 1997;46:25-26

115. Finklestein SP, Weintraub RJ, Karmouz N, Askinazi C, Davar G, Baldessarini RJ. Antidepressant drug treatment for poststroke depression: retrospective study. Arch Phys Med Rehabil 1987;68:772-776

116. Martensson B, Murray V, von Arbin M, Asberg M, Bartfai A, Malm K. Alternative treatment of poststroke depression [letter]. Am J Psychiatry 1997;154:583-584

117. Lauritzen L, Bendsen BB, Vilmar T, Bendsen EB, Lunde $\mathrm{M}$, Bech P. Post-stroke depression: combined treatment with imipramine or desipramine and mianserin: a controlled clinical study. Psychopharmacology (Berl) 1994;114:119_ 122

118. Gonzalez-Torrecillas JL, Mendlewicz J, Lobo A. Effects of early treatment of poststroke depression on neuropsychological rehabilitation. Int Psychogeriatr 1995;7:547-560

119. Spalletta G, Caltagirone C. Sertraline treatment of poststroke major depression: an open study in patients with moderate to severe symptoms. Funct Neurol 2003;18:227232 
120. Lincoln NB, Flannaghan T, Sutcliffe L, Rother L. Evaluation of cognitive behavioural treatment for depression after stroke: a pilot study. Clin Rehabil 1997;11:114-122

121. Currier MB, Murray GB, Welch CC. Electroconvulsive therapy for post-stroke depressed geriatric patients. J Neuropsychiatry Clin Neurosci 1992;4:140-144

122. Boter H, HESTIA Study Group. Multicenter randomized controlled trial of an outreach nursing support program for recently discharged stroke patients. Stroke 2004;35:28672872

123. Smith J, Forster A, Young J. A randomized trial to evaluate an education programme for patients and carers after stroke. Clin Rehabil 2004;18:726-736

124. Simon GE, Ludman EJ, Tutty S, Operskalski B, Von Korff M. Telephone psychotherapy and telephone care management for primary care patients starting antidepressant treatment: a randomized controlled trial. JAMA 2004;292: 935-942
125. Eriksson M, Asplund K, Glader EL, et al. Riks-Stroke Collaboration. Self-reported depression and use of antidepressants after stroke: a national survey. Stroke 2004;35: 936-941

126. Jorge RE, Robinson RG, Arndt S, Starkstein S. Mortality and poststroke depression: a placebo-controlled trial of antidepressants. Am J Psychiatry 2003;160:1823-1829

127. Narushima K, Robinson RG. The effect of early versus late antidepressant treatment on physical impairment associated with poststroke depression: is there a time-related therapeutic window? J Nerv Ment Dis 2003;191:645-652

128. Williams LS, Jones WJ, Shen J, Robinson RL, Kroenke K. Outcomes of newly referred neurology outpatients with depression and pain. Neurology 2004;63:674-677

129. Neumeyer-Gromen A, Lampert T, Stark K, Kallischnigg G. Disease management programs for depression: a systematic review and meta-analysis of randomized controlled trials. Med Care 2004;42:1211-1221 